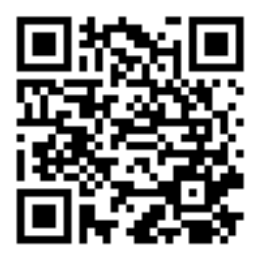

This work has been submitted to NECTAR, the Northampton Electronic Collection of Theses and Research.

http:// nectar.northampton.ac.uk/ 3664/

Creator(s): Seddon, F.

Title: Collaborative computer-mediated music composition in cyberspace

Date: 2006

Originally published by: British J ournal of Music Education

Example citation: Seddon, F. (2006) Collaborative computer-mediated music composition in cyberspace. British Journal of Music

Education. 23(3), pp. 273-283. 0265-0517.

Version of item: Published version

(c) Cambridge University Press. Originally published in British Journal of Music Education. 


\title{
Collaborative computer-mediated music composition in cyberspace
}

\author{
Frederick A. Seddon \\ 27 North 13th street, Milton Keynes, Buckinghamshire, HK9 3NR \\ f.a.seddon@hotmail.co.uk
}

This article reports on an exploratory investigation of the relationship between prior experience of formal instrumental music tuition (FIMT) and the process of collaborative computer-based music composition. The study linked a school in the UK with a school in Norway to engage in computer-mediated collaborative composition via e-mail. Participants were grouped into composing pairs (one from each country) balanced for prior musical experience. Results revealed prior experience of FIMT was associated with extended and complex musical dialogues, critical engagement with musical ideas and produced an 'exploratory' environment. No prior experience of FIMT was associated with uncritical and descriptive dialogues and a 'cumulative' environment. Proposals for future research are discussed.

\section{Introduction}

Information Communication Technology (ICT) is driving change in teaching and research in education (Cain, 2004; Seddon, 2004). In many domains ICT is often employed to facilitate more student-centred learning. This technology makes it possible for teachers, students and researchers to form cohorts from anywhere in the world to transmit information and share expertise. The music education community has been slow to adopt the potential collaborative advantages that more powerful computers, music software and electronic communication can provide (Rees, 2002), possibly because of a degree of scepticism, a lack of access to the technology and an element of discomfort in learning to use these computer-based systems (Rees, 2002; Seddon, 2004). Asynchronous collaboration (i.e. not in real time), through the exchange of music and text files via the Internet or e-mail, is now possible. This asynchronous facility lends itself to promoting collaborative learning in the musical domain especially in collaborative computer-based composition.

Collaborative learning takes place when groups of learners work together to solve a problem and during the process foster cognitive development that is built on past experiences and knowledge (Rogoff, 1990; Howe et al., 1995). Self- and peer-critique and constructive criticism produce learning outcomes that are more successful than when learners work alone (Blaye et al., 1991; Crook, 1999, 2000). Most research into collaborative music composition has been conducted in face-to-face situations (e.g. Morgan et al., 2000; MacDonald \& Miell, 2000). This research established the concept of 'musical dialogue' i.e. musical interaction between collaborating participants, which Morgan et al. (2000) found to be an important feature of collaborative composition. MacDonald and Miell 
(2000) coded both verbal and musical dialogue revealing the importance of friendship in composing dyads. They reported that when composing dyads consisted of one musically trained participant (between 6-72 months of instrumental lessons) and one untrained participant, the trained participant developed their partner's musical ideas more than the untrained participants did and generally displayed more confidence when composing. Seddon and O'Neill $(2001,2006)$ also reported that musically trained participants displayed more self-perceived competence in their ability to compose than their untrained peers.

Most online collaborative music composition projects have focused on experienced mentors teaching composition practices to student composers by linking expert composers with students during the composition process. One example, Composers in Electronic Residence (CIER), was initiated in Canada in 1995 by David Beckstead and involved the music faculties of the Universities of York and Simon Fraser, the Canadian Music Centre, five public schools and two composers (CIER was extended to 15 schools and five composers in 1997). In this project school-aged students were able to meet with composers online to discuss their compositions or to send their compositions to the composers for feedback and direction (http://www.edu.yorku.ca/CIER/Page2.html) (Rees, 2002). In 1999 and 2001 Reese conducted studies designed to test the feasibility of the online mentoring of secondary school pupils by student music teachers. These studies tested the technological viability of online mentoring, the student teachers' attitudes to composition mentoring, and the attitudes of recipient secondary school pupils. Reese employed standard music sequencing software (Musicshop) and 'First Class', a widely available online conferencing tool. Reese found that online mentoring was technologically feasible using these tools but Internet connections were sometimes problematic. Results of the project showed student teacher mentor's attitudes and confidence significantly improved but there were no significant improvements in pupil attitudes (Reese, 1999, 2001).

The Vermont MIDI Project (Cosenza \& MacLeod, 1998; http://www.vtmidi.org/) represented a move towards peer-evaluation. It connected 60 schools in the state of Vermont in an online mentoring project for children across junior and secondary age ranges (K1-12 in USA) which again made available teacher and composer mentors but also included some peer mentoring. Outcomes of this project for the pupils were increased levels of motivation, enhanced music analysis and evaluation skills and the acquisition of a more sophisticated musical vocabulary (Cosenza \& MacLeod, 1998).

The studies discussed above provide evidence that ICT can technologically deliver music e-learning environments in which collaborative music composition activities can take place (Rees, 2002; Reese, 1999, 2001). E-learning environments that foster peer mentoring and evaluation have been shown to result in increased motivation and more effective learning outcomes (Cosenza \& MacLeod, 1998). However, providing an e-learning environment for computer-based composition does not guarantee that collaborative learning will be an outcome (Kreijns et al., 2003). There is empirical evidence that the cognitive processes required to produce deep learning and retention occur in dialogues (Van der Linden \& Renshaw, 2001). However, collaborative learning in asynchronous learning groups in e-learning environments often lack the social interaction needed to produce these dialogues (Hallet \& Cummings, 1997; Wegerif, 1998; Dreyfus, 2001).

There is often confusion between collaborative learning and cooperative learning. Collaboration is more a philosophy of interaction with participants making a coordinated 
effort to solve the problem together whereas cooperation is specific interaction designed to accomplish an end product through the division of labour (Roschelle \& Teasley, 1995). The outcome of collaborative learning is characterised as deep level learning, critical thinking, shared understanding and long-term retention of the learned material (Johnson \& Johnson, 1999; Garrison et al., 2001). It can also result in improved social and communication skills and positive relationships with collaborators (Johnson \& Johnson, 1989, 1999). At its best collaborative learning transcends problem solving and becomes problem defining (Kirschner et al., 1997). Productive dialogue between collaborators is fundamental to effective collaborative learning and the most productive dialogue is 'exploratory talk' (Mercer \& Wegerif, 1999). Mercer and Wegerif (1999) identified three types of talk: (a) disputational talk, which is characterised by disagreement and individualised decision making; (b) cumulative talk, where speakers build positively but uncritically on what the other has said; and (c) exploratory talk, when partners engage constructively with each other's ideas. Morgan et al. (2000) identified 'exploratory play' in musical dialogue but found no links between the extent of musical dialogue and levels of group productivity. The current study set out to investigate communication processes and composition strategies adopted by participant adolescents, with and without prior experience of formal instrumental music tuition (FIMT), during collaborative computer-based composition between countries via e-mail.

\section{Research aims and methods}

The music e-learning environments reviewed above did not focus on facilitating collaborative composition projects between peers, without teacher or expert composer mentoring. The current research was designed to focus mainly on peer interaction by initiating collaborative computer-mediated composition via e-mail between the participants without any mentoring. The study aimed to reveal communication processes and composition strategies adopted by the participants in this 'virtual' environment. The main aims of the study were: (a) to test the logistics of collaborative computer-mediated composition via e-mail; and (b) to investigate the relationship between prior experience of FIMT and both the communication processes and composition strategies adopted. The small pilot study was experimental and investigative in design, grouping individuals into composing pairs balanced for prior experience of FIMT. Prior experience of FIMT in the study was based on whether the participants had or had not received a minimum of 4 years of instrumental lessons, in addition to usual classroom based instrumental activities. A period of 4 years' prior experience of FIMT was chosen based on the results of a previous study (Seddon \& O'Neill, 2003). Seddon and O'Neill's study reported that individuals with or without 4 years' prior experience of FIMT adopted significantly different approaches to composition in relation to levels of 'exploration' when engaged in a computer-based composition task.

Eight participants (four Norwegian, four English) aged 13-14 years were invited by the music teachers in each school to participate in the study. The participants formed four composition pairs, one from each country. Pair 1 were both non-FIMT, Pair 2 were both FIMT, Pair 3 were one FIMT (UK) and one non-FIMT (Norway), and Pair 4 were one FIMT (Norway) and one non-FIMT (UK). Materials included MIDI musical keyboards and 
microphones connected to computers with 'Musit Interactive' music sequencing software installed. This music sequencing software functions similarly to other music sequencing software commercially available (e.g. Cubase or Cakewalk) but also contains an integral 'text box' that enables text communication within the software. Musit Interactive also has an internal file compression system that 'packs' and 'unpacks' the music and text files automatically without the user having to learn additional computer skills. This automatic compression system reduces the file size, simplifying the process of e-mailing music and text files between participants. Musical 'loops' produced by professional musicians were available within Musit Interactive. It was possible for participants to manipulate the position of these 'loops' in the music-sequencing program and to add further MIDI musical material via the MIDI keyboards. The 'loops' were provided as a stimulus for initiating the composition process. Live sounds could also be added by recording into the musicsequencing program via the microphone; they were then saved as audio files. The software also provided an opportunity for participants to communicate by text by embedding text messages within the music file in a drop-down 'Text Box' that formed part of the musicsequencing program.

This technology proved to be easy for the participants to use after only one 10-minute group training session given in each country even though the participants had no prior experience of any music sequencing software. The composition process was initiated in the UK with the instruction 'Using the equipment provided and working with your partner using the 'text box', produce a piece you both agree sounds good'. Each composing pair had six composition sessions (three in each country) each session lasted approximately 25 minutes and took place over 3 consecutive days. After each composition session the evolving compositions were automatically compressed by the Musit Interactive program, saved in separate files, and then e-mailed between UK and Norway until completion of the composition process. This process produced six music files with six embedded text files for each composing pair.

\section{Analysis}

The embedded text communications were analysed employing a procedure used for the qualitative analysis of text known as 'constant comparative method' (Lincoln \& Guba, 1985) based on 'Grounded Theory' (Glaser \& Strauss, 1967). Music files were subjected to repeated listening and categorisation by the researchers, who were all trained musicians, based on an adaptation of constant comparative method validated in a previous study (Seddon \& O'Neill, 2003). The strength of these analysis processes lies in the process allowing for the emergence of themes and categories through a process of inductive reasoning rather than being specified in advance with the data being allocated to predetermined categories. This process revealed text dialogue, musical dialogue, and different composition strategies adopted by the composing pairs. Comparisons were made between the music and text files within each composing pair and between composing pairs. Different themes emerged from the embedded text communication and music files that were categorised and subsequently interpreted by the researchers. 


\section{Results}

Results from the composition process data confirmed that communication during the composition process was taking place on two levels i.e. through both text and music dialogue. The analyses conducted made it possible to compare the embedded text communication and musical communication within and between the composing pairs.

\section{Embedded text communication}

Most of the embedded text communication was relatively short and was categorised by the researchers according to comment style. The categories of text comment styles were interpreted as 'descriptive' (e.g. 'I recorded a sound on the keyboard and used a loop'), 'active' (e.g. 'Put some beat between 40 and 70'), 'evaluative' (e.g. 'I think it sounds OK but could sound a bit better') and 'social' (e.g. 'Thank you Josh'). Once the text communication had been categorised it was possible to plot the distribution of the categories between the composing pairs (see Table 1).

This distribution of comments facilitated the definition of the relative text communication style for each pair in terms of being 'descriptive', 'active', 'evaluative' and 'social'. The text communication between Pair 1 (both Non-FIMT) was largely descriptive; between Pair 2 (both FIMT) it was largely active and evaluative with little social interaction; between Pair 3 (UK FIMT: Norway Non-FIMT) it was largely descriptive and evaluative; between Pair 4 (UK Non-FIMT: Norway FIMT) it was largely descriptive, active and social with an absence of evaluative comments.

Table 1 The distribution of the text communication categories between the composing pairs

\begin{tabular}{lllll}
\hline \hline Text Style & Pair 1 & Pair 2 & Pair 3 & Pair 4 \\
\hline Descriptive Comments (total) & $\mathbf{6}$ & $\mathbf{3}$ & $\mathbf{5}$ & $\mathbf{5}$ \\
$\quad$ Description of action & 6 & 3 & 5 & 5 \\
Active Comments (total) & $\mathbf{1}$ & $\mathbf{4}$ & $\mathbf{1}$ & $\mathbf{5}$ \\
Invitation to add & 0 & 3 & 0 & 3 \\
Invitation to change & 1 & 1 & 1 & 2 \\
Evaluative Comments (total) & $\mathbf{2}$ & $\mathbf{4}$ & $\mathbf{4}$ & $\mathbf{0}$ \\
Self-evaluation & 0 & 2 & 2 & 0 \\
Partner-evaluation & 1 & 1 & 2 & 0 \\
Seeking evaluation & 1 & 1 & 0 & 0 \\
Social Interaction (total) & $\mathbf{2}$ & $\mathbf{1}$ & $\mathbf{2}$ & $\mathbf{8}$ \\
Greeting & 1 & 1 & 1 & 1 \\
Use of name & 0 & 0 & 0 & 3 \\
Thanks expressed & 0 & 0 & 1 & 1 \\
Explanation & 1 & 0 & 0 & 3 \\
\hline \hline
\end{tabular}

Subdivisions of categories combine to give main categories (bold) 


\section{Musical communication}

The musical communication process is revealed through the music files saved at the end of each composing session in each country.

Pair 1 (both non-FIMT). The musical material produced by this non-FIMT composing pair was produced in the form of consecutive musical extensions that followed on from what the composing partner produced the previous day. There was very little evidence of interaction between the musical parts until the final changes made by the Norwegian participant on day 3 and even then the musical dialogue consisted of 'filling in the gaps/silences' left by previous musical statements. Also, when compared to the other pairs' musical dialogue Pair 1's initial musical statement is very short and the piece is short overall. When the musical dialogue between participants in this pair was compared with their embedded text dialogue i.e. 'largely descriptive' (see Table 1) certain similarities emerged. Their consecutive extension musical dialogue was regarded as being similar in nature to their text dialogue in that both dialogues revealed low levels of interaction between the participants. The only text dialogue that was non-descriptive consisted of 'I don't really mind what is done' (invitation to change), 'I like what has been done to the project' (partner evaluation), 'I hope you like this too' (seeking evaluation). There was an 'explanation' provided for deleting the 'gunshots' (a sound effect), 'I didn't like the gunshots that well so I deleted it'. The researchers interpreted all these comments as confrontation avoidance statements. One interpretation of the musical and text dialogue between this pair was that there was little, if any, creative collaboration between the pair and their musical and text dialogue represented a cooperation to complete the task without conflict.

Pair 2 (both FIMT). This FIMT composing pair began overlapping their musical material immediately the collaborative composing process began, engaging with each other's musical material in an interactive way. When the musical dialogue between this pair was compared with their text dialogue i.e. 'largely active and evaluative with little social interaction' (see Table 1) certain similarities were revealed. This pair displayed interactive communication at both music and text levels. For example, there was more interactive musical dialogue with the majority of musical additions overlapping.

This pair's text dialogue was less descriptive than Pair 1 and invited change (e.g. 'Put some beat between 40 and $70^{\prime}$ ) with the work constantly being evaluated (e.g. 'On the midi bit, I like the end of it'). Comparisons between pairs revealed that the musical dialogue between Pair 2 was considerably more complex when compared with Pair 1's musical dialogue. This pair's initial musical statement is relatively long and complex when compared with Pair 1 and the overall length also is much longer than Pair 1's composition. The relative complexity of Pair 2's musical dialogue could indicate that the participants in this pair preferred to communicate through musical dialogue rather than text dialogue. 
Pair 3 (UK FIMT Norway Non-FIMT). The musical material produced by this mixed musical experience composing pair displayed an interactive component through the overlapping of musical material (as with Pair 2). Also, when the researchers listened to the musical material, the concluding sound of each participant's composition session was interpreted by the researchers as 'invitational'. The text dialogue for this pair was found to be predominantly descriptive and evaluative with little active dialogue. Their evaluative comments were very encouraging to each other but they hardly ever invited or tried to direct each other to change anything. One explanation for the lack of active dialogue between this pair could be that, as the concluding musical material in each composition session 'invited' engagement with the partner's material, text dialogue was superfluous. Apart from Pair 1, this pair had the lowest number of active comments and like Pair 1 a high number of descriptive comments. However, they differed from Pair 1 in the greater level of evaluation, longer length and complexity of the piece, which indicated a more collaborative engagement in the process of composition than Pair 1.

Pair 4 (UK Non-FIMT Norway FIMT). The musical material produced by this mixed musical experience composing pair displayed an interactive component through the overlapping of musical material (as with Pairs 2 and 3). However, when listened to by the researchers the musical material was found to be disjointed and culminated in the Norwegian participant more than doubling the length of the piece in the final composition session which left the UK participant no opportunity for response. The text dialogue revealed the highest level of social interaction of all four pairs with comparatively high levels of descriptive dialogue and invitations to action but no evaluation. This pair's collaborative communication in relation to the composition process itself was largely superficial and unlike Pair 3 was not replaced by musical communication.

\section{Discussion}

The main aims of the study were achieved: (a) it proved possible for the participants to engage in collaborative computer-based composition via e-mail between the two countries; and (b) relationships between prior experience of FIMT and communication styles and composition strategies were revealed. There was evidence that the technology facilitated communication on two levels (i.e. music and text). This supported the findings of Morgan et al. (2000) and MacDonald et al. (2000), confirming the existence and importance of musical dialogue. Through examining the relationship between FIMT and the composition process it was revealed that all four composing pairs had different styles of musical and text communications and adopted different composing strategies. Pair 1 (Both Non-FIMT) displayed little interactive involvement at either a musical or text level preferring to cooperate rather than collaborate in an uncritical 'cumulative' style to complete the task with little exploration reducing any possible conflict. This could be interpreted as a lack of selfperceived competence in their ability to compose collaboratively in this environment. Some support for this interpretation can be found in the results of Seddon and O'Neill (2001, 2006) which linked lower levels of self-perceived competence in music composition with 
lack of FIMT when participants composed individually. The current study revealed links between higher levels of exploratory behaviour and prior experience of FIMT. This finding contradicted reported links between prior musical training and lower exploratory behaviour (Scripp et al., 1988; Folkestad, 1991, 1998; Seddon \& O'Neill, 2003). Further research is required to examine the influences of 'virtual' and 'real' environments and prior musical experience on exploratory behaviour during collaborative computer-based composition.

Results in the current study revealed that some participants preferred to communicate through musical dialogue rather than text dialogue to negotiate their actions. This raises the question of language in the current study. English is taught in Norwegian schools and the Norwegian participants' English language skills were thought by the Norwegian teachers to be adequate for the text communication in this context. Also, none of the Norwegian participants expressed any concerns over communicating in English. However, it is possible that some participants were defaulting to musical dialogue as a consequence of not being allowed to use their native language which impaired their communication at a text level. Furthermore, differences in the music curriculum in England and Norway could have influenced the participant responses in this study. Future studies should address these possible confounds, for example through automated interpretation procedures and a review of the similarities and differences of music curricula in both countries. In the current study, Pair 4 displayed relatively high levels of social interaction and zero evaluation in their text dialogue and their musical dialogue although appearing to be interactive was considered by the researchers to be quite musically disjointed displaying little evidence of collaboration or real communication. These results supported Kreijns et al. (2003) who found that providing a collaborative environment does not in itself ensure collaborative engagement. Pairs 2 and 3 could be said to have interacted in a collaborative way to complete the composition task but pairs 1 and 4 interacted in a cooperative way and completed the composition task through a division of labour, lending support to the different communication styles reported by Roschelle \& Teasley (1995).

From an overview of communication style in the current study including both music and text communication) it could be argued that for these participant pairs the presence of a participant with FIMT (Pairs 2, 3 and 4) resulted in relatively extended and complex musical dialogue. When both partners had prior experience of FIMT (Pair 2) musical dialogue replaced descriptive text dialogue and produced an exploratory environment that included critical engagement with each other's ideas. When only one of the pair had prior experience of FIMT this resulted in either descriptive text still being required with the musical dialogue inviting action (Pair 3) or the musical communication breaking down and being replaced by high levels of social interaction via text communication (Pair 4). When the pair was made up of Non-FIMT participants (Pair 1) little if any musical communication took place and an uncritical environment was produced. This would tend to suggest the most effective pairing for composition purposes is both participants having prior experience of FIMT, but that FIMT/Non-FIMT pairings can be more effective in some cases than pairs of Non-FIMT participants. This is an important finding as future larger scale research of this nature could reveal effective groupings for collaborative composition in virtual environments.

The number of participants involved in this study and the analysis procedures employed make it impossible to generalise from the results. However, although small scale and 
exploratory in nature, the results provide a useful framework for future studies. The current study provides method and analyses procedures that could be developed in a future largescale study. It would be interesting to adopt a more naturalistic and longitudinal design, still with a small number of participants, but over a longer period of time. This could reveal more effectively the influence of collaboration in a music e-learning environment. This research could examine the effects of the familiarity of the participants i.e. friendship pairs (MacDonald et al., 2000) and longer periods of experience with the technology on the composition strategies and compositions produced during computer-mediated collaborative composition in a 'virtual' environment. The results of this study provide interesting similarities between the current study's participant text and musical dialogue and 'Cumulative' and 'Exploratory' talk (Mercer, 1994; Mercer \& Wegerif, 1999), which Mercer believes helps us to understand how children 'think together'. In the current study, there were examples of avoidance of 'Disputational' dialogue and engagement in 'Cumulative' and 'Exploratory' dialogue with Exploratory dialogue being related to more successful collaboration processes. To the author's knowledge, these areas of study have not yet been investigated within this particular context. Future studies based on the design of this investigative study could develop research into the relationship between prior musical experience and collaborative computer-based composition in virtual environments.

\section{Acknowledgements}

The author would like to thank the participants and their teachers for taking part in this study. I am also grateful for the technical support provided by Norwegian colleagues Gisle Johnsen and Yrjan Tangenes of Musit Interactive Technology, Bergen, Norway. Finally, I would like to thank Mathilda Joubert for helpful comments and suggestions during the design stage of the study.

\section{References}

BLAYE, A., LIGHT, P., JOINER, R. \& SHELDON, S. (1991) 'Collaboration as a facilitator of planning and problem solving on a computer-based task', British Journal of Developmental Psychology, 9, 47183.

CAIN, T. (2004) 'Theory, technology and the music curriculum', British Journal of Music Education, 21, 2, 215-21.

COSENZA, G. \& MACLEOD, S. (1998) 'Vermont MIDI distance learning network: A model for technology in classroom music', in S. D. Lipscombe (Ed), Proceedings of the Fifth International Technological Directions in Music Learning Conference (pp. 137-8). San Antonio, TX: Institute for Music Research.

CROOK, C. (1999) 'Computers in the community of classrooms', in K. Littleton \& P Light (Eds) Learning with Computers: Analysing productive interaction (pp. 102-17). London \& New York: Routledge.

CROOK, C. (2000) 'Motivation and the ecology of collaborative learning', in R. Joiner, K. Littleton, D. Faulkner \& D. Miell (Eds) Rethinking Collaborative Learning (pp. 161-79). London: Free Association Books.

DREYFUS, H. L. (2001) On the Internet. London \& New York: Routledge.

FOLKESTAD, G. (1991) Music Composition in the Upper Primary School with the help of SynthesisersSequencers, Report No. 1991: 19. Stockholm: Centre for Research in Music Education. 
FOLKESTAD, G. (1998) 'Musical learning as cultural practice: as exemplified in computer-based creative music making', in B. Sundin, G. E. McPherson \& G. Folkestad (Eds) Children Composing: Research in Music Education (pp. 134-46). Malmo: Malmo Academy of Music, Lund University.

GARRISON, D. R., ANDERSON, T. \& ARCHER, W. (2001) Critical thinking and computer conferencing; a model and tool to access cognitive presence. American Journal of Distance Education 15, 1, 7-23.

GLASER, B. G. \& STRAUSS, A. L. (1967) The Discovery of Grounded Theory. Chicago, IL: Aldine.

HALLET, K. \& CUMMINGS, J. (1997) The virtual classroom as authentic experience. In Proceedings of the Annual Conference on Distance Teaching and Learning: Competition-Connection-Collaboration (pp. 103-7), Madison, WI: University of Wisconsin-Madison.

HOWE, C. J., TOLMIE, A., GREER, K. \& MACKENZIE, M. (1995) 'Peer collaboration and conceptual growth in physics: task influences an children's understanding of heating and cooling', Cognition and Instruction, 13, 483-503.

JOHNSON, D. W. \& JOHNSON, R. T. (1989) Cooperation and Learning: Theory and Research. Edina, MN: Interaction Book Company.

JOHNSON, D. W. \& JOHNSON, R. T. (1999) Learning Together and Alone: Cooperative, Competitive, and Individualistic Learning (5th edn), Boston: Allyn \& Bacon.

KIRSCHNER, P. A., VAN VILSTEREN, P., HUMMEL, H. \& WIGMAN, M. (1997) 'A study environment for acquiring academic and professional competence', Studies of Higher Education 22, 2, 151-71.

KREIJNS, K., KIRSCHNER, P. A. \& JOCHEMS, W. (2003) 'Identifying the pitfalls for social interaction in computer-supported collaborative learning environments: a view of the research', Computers in Human Behaviour, 19, 335-53.

LINCOLN, Y. \& GUBA, E. (1985) Naturalistic Enquiry. Beverly Hills, CA: Sage.

MACDONALD, R. \& MIELL, D. (2000) 'Musical conversations: collaborating with a friend on creative tasks', in R. Joiner, K. Littleton, D. Faulkner \& D. Miell (Eds) Rethinking Collaborative Learning (pp. 65-80). London: Free Association Books.

MERCER, N. (1994) 'The quality of talk in children's joint activity at the computer', Journal of Computer Assisted Learning, 10, 24-32.

MERCER, N. \& WEGERIF, R. (1999) 'Is 'exploratory talk' productive talk?', in K. Littleton \& P. Light (Eds) Learning with Computers: Analysing Productive Interaction (pp. 79-101). London \& New York: Routledge.

MORGAN, L., HARGREAVES, D. \& JOINER, R. (2000) 'Children's collaborative music composition: communication through music', in R. Joiner, K. Littleton, D. Faulkner \& D. Miell (Eds) Rethinking Collaborative Learning (pp. 52-64). London: Free Association Books.

REES, F. J. (2002) Distance learning and collaboration in music education. In R. Coldwell \& C. Richardson (Eds) The New Handbook of Research on Music Teaching and Learning (pp. 257-273). Oxford: Oxford University Press.

REESE, S. (1999) 'Potential and problems of Internet-based music composition mentoring', Southeast Journal of Music Education 11, 1-11.

REESE, S. (2001) 'Integration of on-line composition mentoring into music teacher education', Contributions to Music Education 28, 1, 9-26.

REESE, S. (2003) 'Responding to Student Compositions', in M. Hickey (Ed.) Why and How to teach Music Composition: a New Horizon for Music Education (pp. 211-32). Lanham, MD: Rowman and Little field Education, with MENC, The National Association for Music Education.

ROGOFF, B. (1990) Apprenticeship in Thinking. New York: Oxford University Press.

ROSCHELLE, J. \& TEASLEY, S. (1995) 'The construction of shared knowledge in collaborative problemsolving', in C. O'Malley (Ed) Computer-supported Collaborative Learning (pp. 69-97). New York: Springer-Verlag.

SCRIPP, L., MEYAARD, J. \& DAVIDSON, L. (1988) 'Discerning musical development: using computers to discover what we know', Journal of Aesthetic Education, 22, 75-88. 
SEDDON, F. A. (2004) 'Inclusive music curricula for the 21st Century', in L. Bartel (Ed) Questioning the Music Education Paradigm (pp. 212-27). Toronto: Canadian Music Educator's Association.

SEDDON, F. A. \& O'NEILL, S. A. (2001) 'An evaluation study of computer-based compositions by children with and without prior experience of formal instrumental music tuition', Psychology of Music 29, 1, $4-19$.

SEDDON, F. A. \& O'NEILL, S. A. (2003) 'Creative thinking processes in adolescent computer-based composition: an analysis of strategies adopted and the influence of instrumental training', Music Education Research 5, 2, 125-37.

SEDDON, F. A. \& O'NEILL, S. A. (2006) 'How does formal instrumental music tuition (FIMT) impact on selfand teacher-evaluations of adolescents' computer-based compositions?', Psychology of Music 34, 1, $27-45$.

VAN DER LINDEN, J. \& RENSHAW, P. (Eds) (2001) Dialogic Learning. Dordrecht: Kluwer Academic Publishers.

WEGERIF, R. (1998) 'The social dimension of asynchronous learning networks', Journal of Asynchronous Learning Networks 2, 1, 34-49.

\section{URLs}

CIER, (1995/7) http://www.edu.yorku.ca/CIER/Page2.html

Cosenza, G. \& MacLeod, S. (1998) http://www.vtmidi.org

Music Manifesto (2004) http://www.music manifesto.co.uk 